\section{Fracture Resistance of Simulated Immature Teeth Reinforced with Different Mineral Aggregate- Based Materials}

\author{
Mariana Travi Pandolfo (D1, Gabriela Rover (D) 1, Eduardo Antunes \\ Bortoluzzi (D1, Cleonice da Silveira Teixeira (D) 1, Hebert Luís \\ Rossetto (1)2, Paula Cristina dos Santos Vaz Fernades (D) 3, Inês \\ Sansonetty Gonçalves Côrte-Real (1) 3, Sandra Maria Fernandes \\ Carvalho (D),5, Lucas da Fonseca Roberti Garcia®1.
}

This study assessed the fracture resistance of simulated immature teeth reinforced with calcium aluminate cement (CAC) or mineral trioxide aggregate (MTA) containing calcium carbonate nanoparticles (nano-CaCO3). The microstructural arrangement of the cements and their chemical constitution were also evaluated. Forty-eight canines simulating immature teeth were distributed into 6 groups $(n=8)$ : Negative control - no apical plug or root canal filling; $C A C$ - apical plug with $C A C ; C A C / n a n o-C a C O 3$ - apical plug with $\mathrm{CAC}+5 \%$ nano-CaCO3; MTA - apical plug with MTA; MTA/nano$\mathrm{CaCO} 3$ - apical plug with MTA+5\% nano-CaCO3; and Positive control - root canal filling with MTA. The fracture resistance was evaluated in a universal testing machine. Samples of the cements were analyzed under Scanning Electron Microscope (SEM) to determine their microstructural arrangement. Chemical analysis of the cements was performed by Energy Dispersive X-ray Spectroscopy (EDS). The fracture resistance of $\mathrm{CAC} /$ nano- $\mathrm{CaCO} 3$ was significantly higher than the negative control $(p<0.05)$. There was no significant difference among the other groups $(p>0.05)$. Both cements had a more regular microstructure with the addition of nano-CaC03. MTA samples had more calcium available in soluble forms than CAC. The addition of nano$\mathrm{CaCO} 3$ to $\mathrm{CAC}$ increased the fracture resistance of teeth in comparison with the non-reinforced teeth. The microstructure of both cements containing nano-CaCO3 was similar, with a more homogeneous distribution of lamellarand prismatic-shaped crystals. MTA had more calcium available in soluble forms than CAC.

\author{
1 Department of Dentistry - Endodontics \\ Division, Health Sciences Center, Federal \\ University of Santa Catarina, Florianópolis, SC, \\ Brazil. \\ 2 Engineering Center, Federal University of \\ Pelotas, Pelotas, RS, Brazil.
3 Department of Fixed Prosthesis, School of Dental Medicine, University of Porto, Porto, \\ Portugal. \\ 4 CEMMPRE - Centre for Mechanical \\ Engineering, Materials and Processes, University \\ of Coimbra, Coimbra, Portugal. \\ 5 CF-UM-UP - Centre of Physics of the \\ Universities of Minho and Porto, Guimarães, \\ Portugal.
}

\begin{abstract}
Correspondence: Prof. Lucas da Fonseca Roberti Garcia - Department of Dentistry, Health Sciences Center, Federal University of Santa Catarina, Campus Reitor João David Ferreira Lima, CEP: 88040-900, Florianópolis, Santa Catarina, Brazil. Telephone: +55 (48) 3721-4853. E-mail address: drlucas.garcia@gmail.com
\end{abstract}

Key Words: Immature Teeth; Calcium Aluminate Cement; Silicate Cement; Calcium Carbonate; Fracture Resistance

\title{
Introduction
}

The endodontic management of permanent immature teeth is challenging due to the wide apical opening and the thin thickness of the root canal walls (1). These teeth are more susceptible to fracture, especially at the cervical third (2). Apexification is the therapy usually indicated in cases of pulp necrosis and incomplete rhizogenesis $(1,2)$.

Mineral Trioxide Aggregate (MTA) may be used to induce apexification due to its bioactivity, high mechanical resistance and good apical sealing ability (3). Despite presenting features and benefits that are favorable to its use, MTA has limitations, such as its long setting time (4) and poor handling characteristics (5). For this reason, other mineral aggregate-based cements have been suggested as promising possibilities for apexification therapy (6).

Calcium aluminate cement (CAC) is a hydraulic binder and it has been highlighted in the literature for presenting adequate properties (7-9). The mechanical resistance (7), biocompatibility (8) and induction of mineralized tissue deposition (9) are some of these features.

Similarly to MTA, CAC also has a sandy consistency, making its manipulation and placement into the endodontic space difficult (7). In order to solve this inconvenience, additives have been associated with mineral aggregate-based cements to improve their physical and chemical properties $(10,11)$.

The nanoparticulate calcium carbonate (nano- $\mathrm{CaCO}$ ) is an additive that showed good results when it was incorporated into mineral aggregate-based cements (10-12). This additive accelerates the initial 
hydration phase of the cements, improving their mechanical resistance and, especially, their manipulation (10-12).

Although the apexification has considerable efficiency in preserving immature teeth, the possibility of root fracture is high $(1,2)$. Considering the limited information regarding the capacity of new mineral aggregate-based cements to strengthen immature teeth, this study evaluated the fracture resistance of teeth reinforced with CAC or MTA containing nano-CaCO3. In addition, the microstructure and the chemical composition of the cements (before and after the addition of nano-CaC03) were also analyzed. The null hypotheses tested were: 1 - the addition of nano-CaCO3 to the cements would not affect the reinforcement of immature teeth; and 2 - the addition of nano-CaCO3 would not modify the microstructure and the chemical composition of the cements.

\section{Materials and methods}

\section{Sample size calculation}

The sample size was calculated with the aid of the G*Power version 3.1.9.6 software (http://www.psycho.uni-duesseldorf.de/abteilungen/aap/gpower3/) to allow an analysis with $\alpha=0.05$, Power $(1-\beta$ err prob) $=0.95$ and effect size $f=0.80$. The ANCOVA (fixed effects, main effects, and interactions) statistical test was performed. The type of power analysis was set a priori (compute required sample size - given $\alpha$, power, and effect size). Therefore, a minimum of 8 teeth were allocated to each of the experimental groups.

\section{Specimen selection and preparation}

This study was previously approved by the Human Research Ethics Committee (reference $n^{\circ}$. 2.766.031). Forty-eight freshly extracted human canines, with fully formed roots, closed apex, a single and straight root canal and similar dimensions were selected for the study. The specimens' dimension was based on the measurement of their buccolingual and mesiodistal dimensions at the cemento-enamel junction. The mean values $(\mathrm{mm})$ were obtained and the teeth displaying more than $20 \%$ deviation were exclude from the study.

After being disinfected in 5\% chloramine T solution and externally cleaned with an ultrasonic tip (Dabi Atlante, Ribeirão Preto, SP, Brazil), the teeth were inspected under magnification (4x). Teeth with carious lesions, cracks or fractures were excluded from the final sample. The selected teeth were individually packed in bottles containing distilled water to prevent dehydration and stored in an oven at $37^{\circ} \mathrm{C}$ until used.

The crowns and roots of the teeth were sectioned $2 \mathrm{~mm}$ above and $11 \mathrm{~mm}$ below the cementoenamel junction, respectively, using a double-sided diamond disc (Fava, São Paulo, SP, Brazil) coupled to a handpiece at low rotation (Model 605; Kavo, Joinville, SC, Brazil) under abundant water cooling to obtain specimens with a total length of $13 \mathrm{~mm}$. The pulp tissue was removed with a size-60 Hedstroem file (Dentsply-Malleifer, Ballaigues, Switzerland) and irrigation was performed with $2 \mathrm{~mL}$ of $1 \%$ sodium hypochlorite solution (Biodinâmica, Ibiporã, PR, Brazil). To simulate teeth with incomplete rhizogenesis, the root canals were enlarged with Peeso drills (No. 1-6; Dentsply-Malleifer) along their entire length. Irrigation was performed with $2 \mathrm{~mL}$ of $1 \%$ sodium hypochlorite solution at each instrument change. The root canal walls at the apical third were enlarged with a carbide drill No. 703 (JET carbide Burs; Beavers Dental Products Ltd., Morrisburg, ON, Canada) coupled to a handpiece at low rotation, in order to obtain $1.5 \mathrm{~mm}$ thick dentin walls, simulating the Cvek stage 3 of root development. The dentin thickness was confirmed with the aid of a digital specimeter (Golgran, São Caetano do Sul, SP, Brazil). A final irrigation with $5 \mathrm{~mL}$ of $1 \%$ sodium hypochlorite, followed by $3 \mathrm{~mL}$ of $17 \%$ EDTA (Biodinâmica) for 3 minutes and $5 \mathrm{~mL}$ of $1 \%$ sodium hypochlorite was performed. Then, the teeth were dried with absorbent paper cones (Dentsply-Malleifer).

After preparation, the specimens were distributed into 6 experimental groups $(n=8)$, as follows (Table 1): 
Table 1. Distribution of the experimental groups according to the cement and the respective powder/liquid proportions used
Groups
Cements
Powder/Liquid Rate
(Water/propylene glycol)

Negative control

no root canal filling

CAC

CAC/nano-CaCO3

MTA

MTA/nano-CaCO3

$$
\begin{gathered}
\text { apical plug }(\mathrm{CAC})+\text { root canal filling } \\
\text { apical plug }(\mathrm{CAC}+5 \% \text { nano-CaCO3) + root canal }
\end{gathered}
$$
filling

apical plug (MTA) + root canal filling apical plug (MTA + 5\% nano-CaCO3) + root canal filling
$1 \mathrm{~g} / 0.21 \mathrm{~mL}$

$0.950 \mathrm{~g} / 0.19 \mathrm{~mL}+0.050 \mathrm{~g} / 0.05 \mathrm{~mL}$

$1 \mathrm{~g} / 0.33 \mathrm{~mL}$

$0.950 \mathrm{~g} / 0.28 \mathrm{~mL}+0.050 \mathrm{~g} / 0.05 \mathrm{~mL}$

Positive control

root canal completely filled with MTA

$1 \mathrm{~g} / 0.33 \mathrm{~mL}$

* The amount of powder and distilled water used for manipulating the cements was calculated according to the amount of nano- $\mathrm{CaCO}_{3}$ and propylene glycol used for manipulating the nano- $\mathrm{CaCO}_{3}$ paste.

Negative control group: no apical plug fabrication or root canal filling was performed.

CAC group: fabrication of an apical plug with $C A C$ and filling of the root canal in its entire length. CAC (EndoBinder; Binderware, São Carlos, SP, Brazil) was manipulated on a glass plate, in the proportion of $1 \mathrm{~g}$ of powder to $0.21 \mathrm{~mL}$ of distilled water, according to the manufacturer's recommendations. The cement was inserted into the root canal with a size-40 Lentulo spiral (Dentsply-Malleifer), coupled to a handpiece at low rotation. The cement was compressed in the apical third of the root canal with a digital condenser, until an apical plug with a thickness of $4 \mathrm{~mm}$ was obtained. The homogeneity of the apical plug was confirmed by radiographic examination, both in buccolingual and mesiodistal directions. A damp paper cone was left in the root canal and the teeth were stored in a $37^{\circ} \mathrm{C}$ oven for 12 hours to allow the complete setting of the cement. After, the root canal was filled with AH Plus sealer (DentsplyHerpo, Petrópolis, RJ, Brazil) and gutta-percha cones (Dentsply-Malleifer) by a carrier-based thermoplasticized gutta-percha technique (Obtura IIIMAX System; Obtura Spartan, Earth City, MO, USA). The quality of the filling was also verified by radiographic examination.

CAC/nano-CaCO3 group: fabrication of an apical plug with CAC containing 5\% nano-CaCO3 (Lagos Indústria Química, Arcos, MG, Brazil). The paste formed from the mixture of $0.050 \mathrm{~g}$ of nano-CaC03 with $0.05 \mathrm{~mL}$ of propylene glycol (dispersant) (11) was incorporated into the CAC, which in turn was manipulated in the proportion of $0.950 \mathrm{~g}$ of powder to $0.19 \mathrm{~mL}$ distilled water, and inserted into the root canal as previously described. The root canal was then filled as described in CAC group.

MTA group: fabrication of an apical plug with MTA and filling of the of the root canal with AH Plus sealer and gutta-percha cones, as described in the previous groups. MTA (Angelus, Londrina, PR, Brazil) was manipulated according to the manufacturer's recommendations, in the proportion of one dose of powder to a drop of distilled water. A damp paper cone was left in the root canal, and the teeth were stored in an oven at $37^{\circ} \mathrm{C}$ for 12 hours to allow complete setting of the cement.

MTA/nano-CaCO3 group: fabrication of an apical plug with MTA containing 5\% nano-CaC03. The paste of nano- $\mathrm{CaCO} 3$ was incorporated into the MTA, which in turn was manipulated in the proportion of $0.950 \mathrm{~g}$ to $0.28 \mathrm{~mL}$ of distilled water (11), and inserted into the root canal as previously described. A damp paper cone was left in the root canal and the teeth were stored in an oven at $37^{\circ} \mathrm{C}$ for 12 hours. The root canal was filled as in the other groups.

Positive control group: the root canals were completely filled with MTA. The cement was manipulated and inserted in the root canal as described in the previous groups, up to the limit of the cementoenamel junction.

The endodontic access was restored with adhesive system (Adper Single Bond 2; 3M ESPE, St. Paul, MN, USA) and composite resin (Filtek Z350 XT; 3M, Sumaré, SP, Brazil). The specimens were individually stored in closed plastic flasks containing distilled water and placed in an incubator at $37^{\circ} \mathrm{C}$ for 48 hours. 
All stages of this research were performed by a single operator, previously trained and specialized in Endodontics.

\section{Fracture resistance test}

The simulation of the periodontal ligament was performed following the methodology proposed by Soares et al. (13). The specimens were submitted to the fracture resistance test in a universal testing machine (EMIC DL200MF; EMIC, São José dos Pinhais, PR, Brazil). They were mounted to a device with a $45^{\circ}$ inclination (Odeme Dental Research, Luzerna, SC, Brazil), which was attached to the bottom of the machine. The teeth received a compression force on the buccal edge, forming an angle of $135^{\circ}$ in relation to their long axis, simulating dental intercuspation. The compression force was applied continuously with a crosshead speed of $0.5 \mathrm{~mm} / \mathrm{min}$, until the tooth fractured.

The fracture modes were classified as "restorable", when the failure was above the acrylic resin (simulated bone level) and "non-restorable", when the failure extended below to the acrylic resin (Figure $1 a-b)(13)$.

(a)
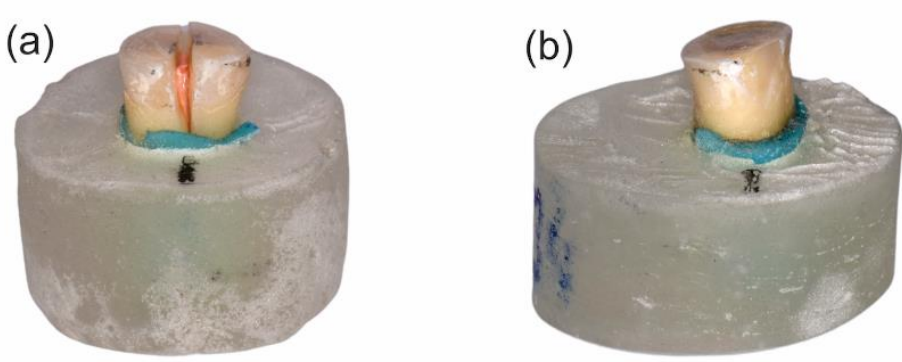

(c)

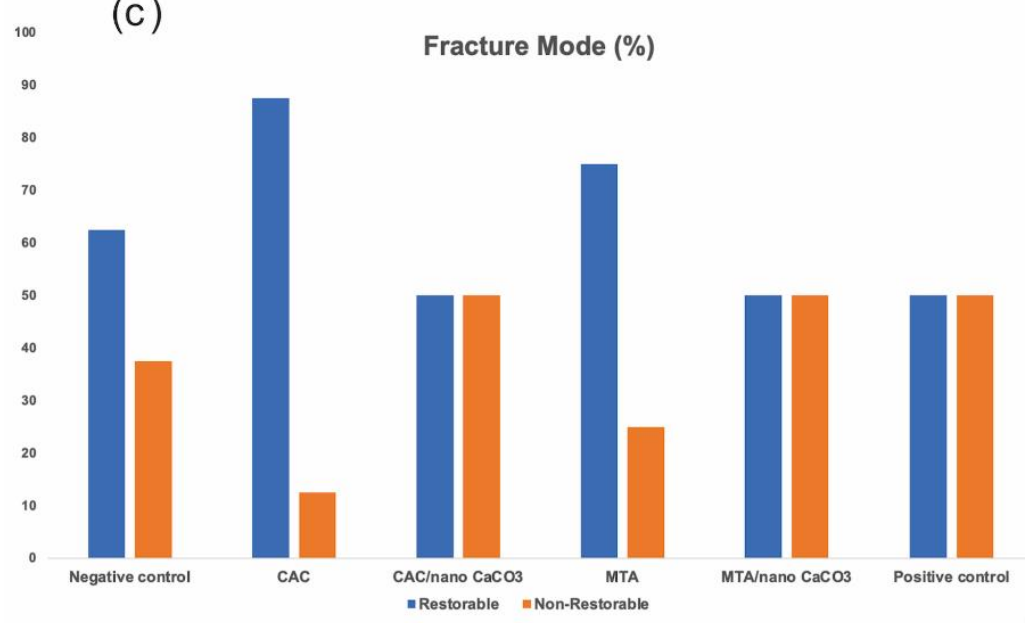

Figure 1. Representative image of fractured specimens classified as "nonrestorable" (a) and "restorable" (b). (c) Fracture mode analysis distribution (\%) according to the experimental groups.

\section{Microstructural and chemical analysis of the cements}

Samples of pure nano-CaCO3, CAC, CAC $+5 \%$ nano-CaCO3, MTA and MTA + 5\% nano-CaCO3 were manipulated as previously described, inserted into a stainless steel matrix $(2 \mathrm{~mm}$ thick $\times 3 \mathrm{~mm}$ in diameter) and submitted to SEM analysis (Nova NanoSEM 200 - FEl, Hillsboro, OR, USA). The samples surface was coated with a thin layer $(20 \mathrm{~nm})$ of gold/palladium alloy and the microstructure of each material was analyzed under magnifications of $7000 x, 15000 x, 25000 x$ and $50000 x$. The chemical analysis of the materials was performed using EDS (EDAX - Pegasus X4M, Inc., Mahwah, NJ, USA).

\section{Statistical analysis}

The statistical analysis was performed using the IBM ${ }^{\circledR}$ SPSS ${ }^{\circledR}$ Statistics (version 21.0) program (SPSS Inc., Chicago, IL, USA). The statistical significance was set at $5 \%(\alpha=0.05)$. The normal distribution of the data was confirmed by the Shapiro-Wilk test $(p>0.05)$ and the homogeneity of the sample was verified using the Levene test. One-way Analysis of Variance (ANOVA) $(\mathrm{p}<0.05)$ was used to compare the results 
among groups and the post hoc Bonferroni test was used to analyze the significant difference among the groups $(p<0.05)$.

\section{Results}

Fracture resistance

The fracture resistance mean values may be seen in Table 2 .

Table 2. Mean values $(\mathrm{N})$ and standard deviation of fracture resistance of the experimental groups

\begin{tabular}{lcc}
\hline \multirow{2}{*}{ Groups } & \multicolumn{2}{c}{ Fracture Resistance } \\
\cline { 2 - 3 } & Mean (N) & Standard Deviation \\
\hline Negative control & $498.85^{\mathrm{b}}$ & 115.43 \\
CAC & $663.96^{\mathrm{ab}}$ & 158.67 \\
CAC/nano-CaCO & & 192.04 \\
MTA & $824.45^{\mathrm{a}}$ & 141.49 \\
MTA/nano-CaCO & $673.99^{\mathrm{ab}}$ & 94.30 \\
Positive control & $674.95^{\mathrm{ab}}$ & 90.84 \\
\hline Lower-case superscipt & $621.29^{\mathrm{ab}}$ & \\
\hline
\end{tabular}

Lower-case superscript letters represent statistically significant difference among groups $(\mathrm{p}<0.05)$.

The fracture resistance in $\mathrm{CAC} /$ nano- $\mathrm{CaCO} 3$ group was significantly higher than the negative control $(p=0.475)$. No significant difference was found in the comparison of fracture resistance among the other experimental groups ( $p>0.05)$.

Regarding the fracture mode analysis (Figure 1c), most of the samples of the negative control, CAC and MTA groups presented "restorable" fractures, while in the CAC/nano-CaCO3, MTA/nano-CaCO3 and positive control groups, half of the samples presented "restorable" fractures and the other half, "nonrestorable" fractures.

\section{Microstructural and chemical analysis}

The analysis of the pure nano-CaCO3 identified its microstructural arrangement and the presence of nanoparticles, which were grouped into clusters, ranging from 15 to $60 \mathrm{~nm}$ (Figure 2). By SEM it was also observed a series of topographical accidents that constitute the microstructure of the cements, such as the formation of hydration channels, pores and grooves (Figure 3). In the MTA group (Figure 3e-f), a microstructure formed by lamellar-shaped crystals was noted. In the CAC group (Figure 3a-b), the crystals had a prismatic shape, with a more homogeneous distribution through the cement microstructure than MTA. When nano-CaCO3 was added to the cements (Figures $3 c-d ; 3 g-h$ ), both had a microstructure with a more regular and less porous shape. In general, the cements were associated with similar topographic accidents in their microstructure, however, these findings were less pronounced in both $\mathrm{CAC}$ versions. When nano- $\mathrm{CaCO} 3$ was added to the cements, these microstructural differences decreased. 


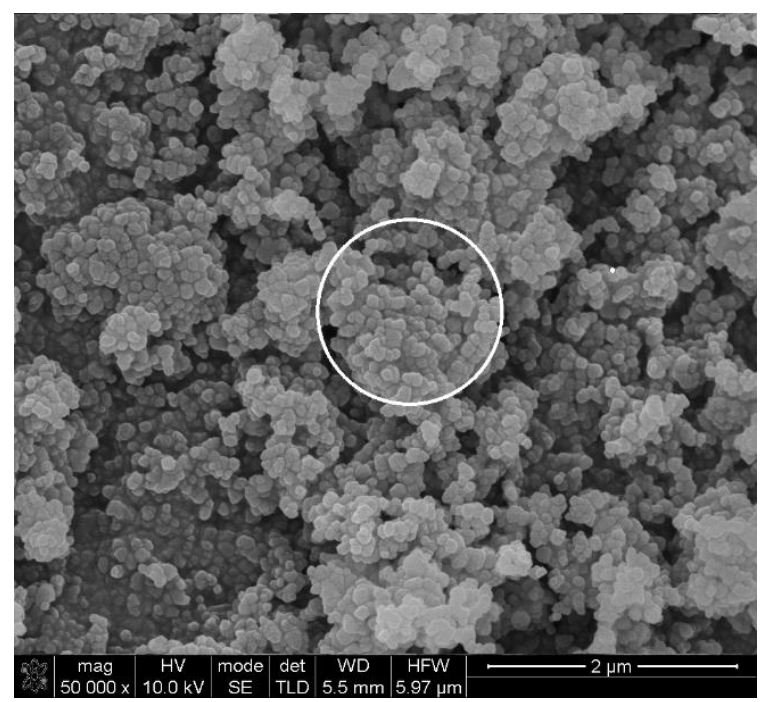

Figure 2. Representative SEM micrograph of a nano-CaCO3 sample. Observe the various nanoparticleclusters ( 15 to 60 $\mathrm{nm}$ ) that compose the additive (circle)

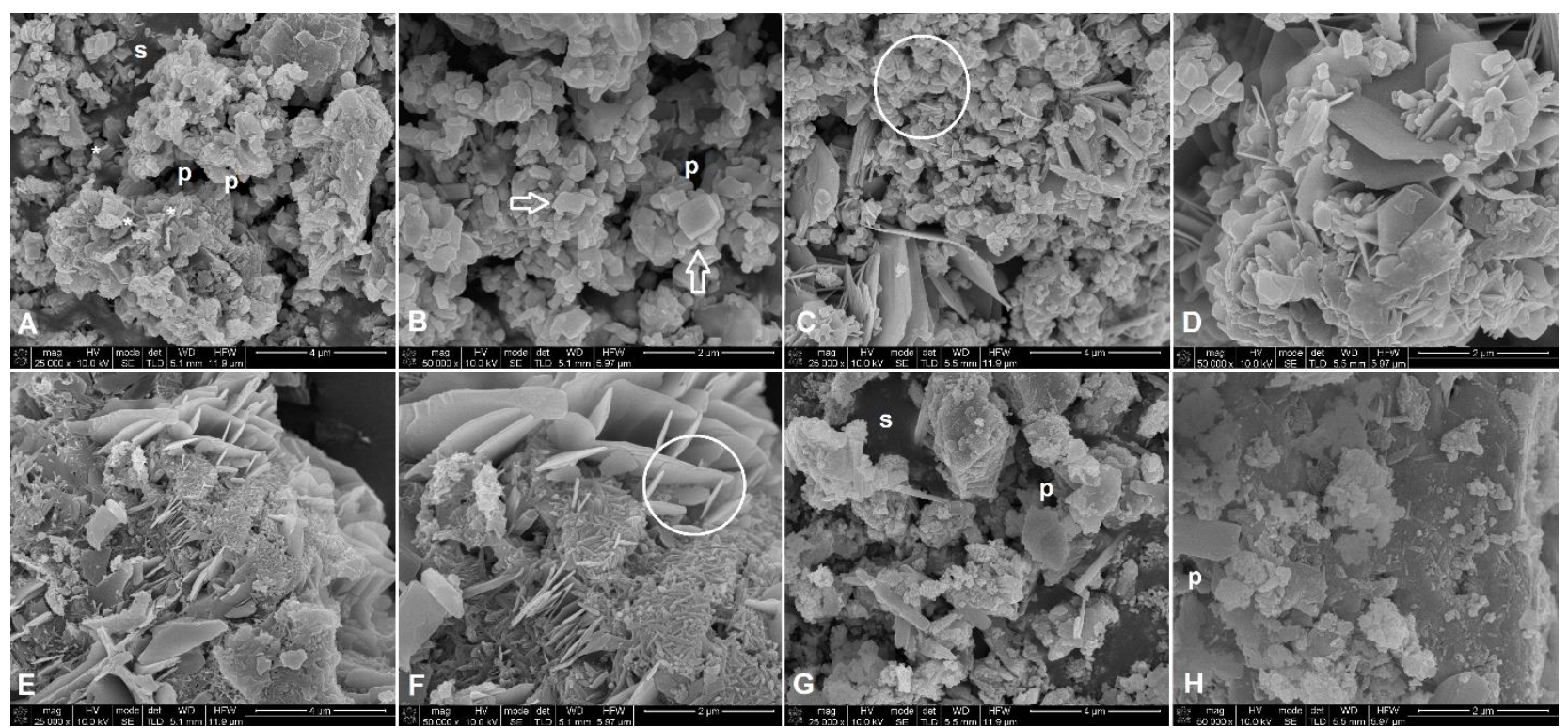

Figure 3. Representative SEM micrographs of samples from the different tested cements, with and without the addition of nanoCaC03. ( $a$ and b) CAC: microstructural arrangement of the cement, with the presence of pores (p) and grooves (s). Note the homogeneity of the cement particles, with a large majority of prismatic shapes (arrows). However, it is possible to observe some lamellar-shaped particles $\left(^{*}\right.$ ). (c and d) CAC/nano-CaC03: smaller number of pores in the cement microstructure, due to the likely occupation of spaces by the nano- $\mathrm{CaCO} 3$ (circle), whose particles may be seen in greater magnification (d). Presence of lamellarshaped structures, characteristics of $\mathrm{Ca}(\mathrm{OH}) 2$ formed by cement hydration. (e and f) MTA: less regular microstructure compared to samples of pure CAC, with heterogeneous distribution of particles of different shapes and sizes. Lamellar-shaped crystals in a larger image (circle), showing the presence of $\mathrm{Ca}(\mathrm{OH}) 2$. ( $\mathrm{g}$ and $\mathrm{h}$ ) MTA/nano- $\mathrm{CaCO}$ : the cement microstructure also shows the presence of topographic accidents, such as pores (p) and grooves (s). In another region (h), it was possible to notice greater homogeneity and structural density of the cement.

The analysis by SEM/EDS identified the main components of each cement (Figure 4). MTA samples presented larger crystals, without iron and aluminium; and less potassium and silicon. In addition, smoother areas with a higher percentage of bismuth were also noted (Figure 4a). The main chemical elements detected in both MTA versions were $\mathrm{O}, \mathrm{Mg}, \mathrm{Al}, \mathrm{Si}, \mathrm{S}, \mathrm{Bi}, \mathrm{K}, \mathrm{Ca}$ and $\mathrm{Fe}$. In CAC, lamellar-shaped particles, containing aluminium and chlorine, were observed. Moreover, few prismatic-shaped particles, with less calcium, chlorine and zinc content were noted (Figure 4b). The components identified in CAC samples were $\mathrm{O}, \mathrm{Al}, \mathrm{Cl}, \mathrm{Ca}$ and $\mathrm{Zn}$. When nano- $\mathrm{CaCO} 3$ was incorporated into the cements, an increase in the amount of $\mathrm{Ca}(\mathrm{wt} \%)$ was observed in the versions containing the additive (MTA - 8.39 31.79 and CAC - 2.67 13.07). Also, the amount of Ca was greater for MTA when compared to CAC, irrespective of the addition of nano-CaCO3. 

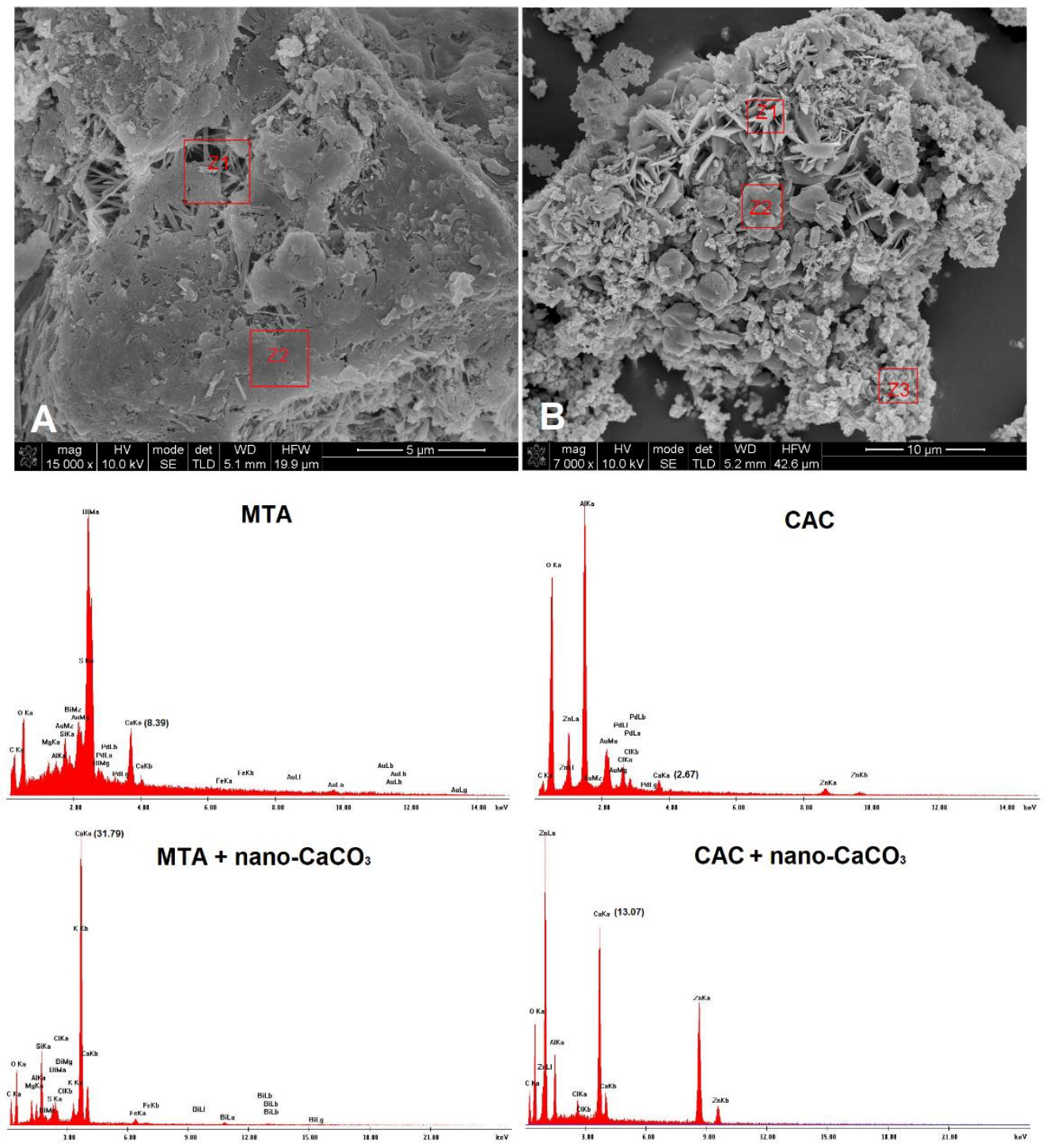

Figure 4. Representative micrographs and respective graphical representations of SEM/EDS of the different tested cements, with and without the addition of nano-CaCO3. (a) MTA: larger crystals, without iron and aluminium; and less potassium and silicon (Z1). There are also smoother areas with a higher percentage of bismuth (Z2). (b) CAC: lamellar-shaped particles, with the presence of aluminium and chlorine (Z1), and prismatic-shaped particles, with little calcium and chlorine (Z2), and zinc (Z3). In the MTA samples (left column) the following chemical elements were detected: $0, \mathrm{Mg}, \mathrm{Al}, \mathrm{Si}, \mathrm{S}, \mathrm{Bi}, \mathrm{K}, \mathrm{Ca}$ and $\mathrm{Fe}_{1}$ with an increase in the amount of $\mathrm{Ca}(\mathrm{wt} \%)$. After the addition of nano-CaCO3 in the composition of the cement. For $\mathrm{CAC}$, the main elements detected were: $\mathrm{O}, \mathrm{Al}, \mathrm{Cl}, \mathrm{Ca}$ and $\mathrm{Zn}$. When nano$\mathrm{CaCO} 3$ was added to $\mathrm{CAC}$ there was no increase in the amount of $\mathrm{Ca}$ in its composition (see note in the peaks).

\section{Discussion}

The purpose of the present study was to evaluate the fracture resistance of simulated immature teeth, reinforced with CAC or MTA containing nano-CaC03. According to the results obtained, the first null hypothesis tested was rejected, since the addition of nano- $\mathrm{CaCO} 3$ to the cements did not increase the fracture resistance of the teeth, in comparison with their versions without the additive. Conversely, the addition of nano- $\mathrm{CaCO} 3$ altered the microstructure of both cements and the amount of $\mathrm{Ca}$ present in the MTA samples, thus, the second null hypothesis was accepted. It is also worth mentioning that the group in which the nano-CaCO3 was added to $\mathrm{CAC}$ had greater fracture resistance than the negative control (no apical plug/root canal filling).

The ideal scenario would be the use of permanent immature human teeth to perform this type of study. However, it is difficult to reach the necessary number of teeth to carry out the study with reliable statistical significance. Therefore, immature teeth were simulated following the methodology of other studies $(2,14,15)$. On the other hand, a greater enlargement of the root canal space at the apical third was performed in the present study. In most of the studies performed so far $(1,2,14,15)$, the root canals 
were enlarged with Peeso drills from No. 1 to 6, with the latter passing $1 \mathrm{~mm}$ beyond the apex. This protocol results in a final dentin thickness ranging from 2.0 to $2.5 \mathrm{~mm}$, which does not accurately simulate the root of an immature tooth (16). Root canal walls with at least $2.63 \mathrm{~mm}$ thick are sufficient to ensure mechanical resistance to the tooth, dispensing the use of materials for additional reinforcement (16). For this reason, the root canal walls were further enlarged, aiming to simulate the Cvek stage 3 of root development, with $1.5 \mathrm{~mm}$ thick dentin walls.

The addition of nano- $\mathrm{CaCO} 3$ accelerates the hydration process of the tricalcium silicate (C3S) and tricalcium aluminate $(\mathrm{C} 3 \mathrm{~A})$ to form calcium silicate hydrate $(\mathrm{C}-\mathrm{S}-\mathrm{H})$ and carboaluminates, respectively (17). The benefits of this addition is effective only when the amount of nano-CaCO3 is increased to some extent $(11,17)$. As the amount of nano-CaCO3 increases, the mechanical resistance of mineral aggregatebased cements also increases $(11,17)$. However, after a longer period, the mechanical resistance of cements containing greater amounts of nano-CaCO3 decreases $(11,17)$. Therefore, 5\% nano-CaCO3 (wt\%) was added to the cements. According to several studies, this amount of nano-CaCO3 improves the handling characteristics, decreases the setting time and does not affect the mechanical resistance of the cements (10-12).

The nanoparticles of $\mathrm{CaCO} 3$ has great surface energy, which tends to cluster during manipulation (10-12), as observed by SEM (Figure 2). The nano-CaCO3 powder was initially manipulated with propylene glycol and then added to CAC and MTA, previously manipulated with distilled water, to prevent the clusters formation (10-12). Propylene glycol increases the flowability of mineral aggregate-based cements, improving their clinical manipulation (18). Its use in large quantities, however, may lead to a longer setting time (18). Thus, the water-to-powder ratio of the cements containing nano-CaCO3 was changed, as the volume of water used for hydration of the binders decreases in this condition (11).

The microstructural analysis of the cements showed a more regular and homogeneous arrangement of the particles when the nano- $\mathrm{CaCO} 3$ was added to them. Such phenomenon may be confirmed by comparing the SEM images of the different versions of both cements (Figures $3 a-b \times 3 c-d$; and Figures $3 e-f \times 3 g-h)$. This finding might be related to the improvement observed in the rheological properties of the cements during their manipulation, corroborating other studies that evaluated mineral aggregatebased cements containing nano-CaCO3 (10-12). The manipulation of these cements is difficult, leading to the incorporation of air bubbles, which makes their microstructure unstable and brittle (7). The nano$\mathrm{CaCO} 3$ particles act as nuclei for reducing the hydration activation energy of the cements, favouring the precipitation of hydrates from their surface, resulting in a more stable microstructure, with particles similar in shape and size (Figures $3 c-d ; 3 g-h)(12)$.

It was observed in both versions of the cements, the presence of lamellar structures (Figures 3c-d; $3 e-f)$ corresponding to the $\mathrm{Ca}(\mathrm{OH}) 2$ formed by the hydration process of the cements (12). This phenomenon corresponds to their hydration kinetics, which leads to $\mathrm{Ca}(\mathrm{OH}) 2$ precipitation, regardless the addition of nano-CaCO3 (19). These lamellae structures are the responsible for the alkalinity of the cements in aqueous medium, which is more pronounced for MTA (20).

The SEM/EDS analysis demonstrated that the addition of nano-CaCO3 increased the amount of $\mathrm{Ca}$ for both cements. However, this increase was greater in MTA samples. This fact may represent changes in the antimicrobial effectiveness and bioactivity of this cement. Conversely, it must be emphasized that an increase in the amount of $\mathrm{Ca}$ in the final cement composition does not necessarily mean a greater release of $\mathrm{Ca}++(20)$. Thus, further studies evaluating the $\mathrm{Ca}++$ release of mineral aggregate-based cements containing nano-CaCO3 should be carried out.

In the present study, only the group in which the apical plug was fabricated with CAC containing nano- $\mathrm{CaCO} 3$ showed greater fracture resistance than the negative control group. The characteristics of the microstructural arrangement of $C A C$, which became more regular after the addition of the nanoparticles (Figure 3c-d) than MTA (Figure 3g-h), may justify the different mechanical behaviour of the cements (7). The similar shape and size of CAC particles, ensure a proper stress distribution through the cement, giving the material higher mechanical resistance (7).

In the other groups, there was no statistically significant difference, regardless of the cement evaluated. This result contrasts with the literature, which it has shown increase in the fracture resistance of permanent immature teeth when reinforced with different mineral aggregate-based cements $(1,2,6)$. This may be attributed to the greater enlargement of the root canal walls at the apical third, which effectively simulated the thickness of the root canal walls of a permanent immature tooth in Cvek stage 3. Indeed, one of the main limitations of this type of study is to simulate a permanent immature tooth as similar as possible to what occurs in clinical conditions (21). For this reason, we believe that the methodology currently used to perform fracture resistance tests in simulated immature teeth must be 
re-evaluated, as they not provide a reliable root canal walls enlargement, as performed in the present study. In addition, even if the teeth used in these studies may perfectly mimic the morphology of the ones with real incomplete rhizogenesis, it is not possible to accurately simulate the composition and physical-mechanical properties of immature teeth (22).

The fracture mode was also analyzed to complement the findings of the fracture resistance test. Fractures at the level of enamel and/or dentin are considered favourable, as they can be repaired, without using any type of intraradicular reinforcement $(23,24)$. However, when the fracture occurs at or below the cementoenamel junction, more complex restorative procedures are necessary to avoid the tooth loss $(23,24)$. In the present study, most of the samples were associated with restorable fractures. However, it is noteworthy that the group which had the best performance regarding fracture resistance (CAC/nano$\mathrm{CaCO} 3$ ) in comparison with the negative control (no reinforcement), half of the samples were associated with a non-restorable fracture.

According to Brito Júnior et al. (25), fracture resistance tests, despite being fundamental to assess the mechanical behavior of teeth, provide limited information regarding the stress distribution under high-intensity load application. Therefore, non-destructive tests, such as the finite element analysis, might be a reliable method to properly understand the fracture mode of immature teeth under stress (25).

Within the limitations of the present study, it was concluded that the calcium aluminate cement associated with calcium carbonate nanoparticles provided greater fracture resistance to immature teeth, when compared to the non-reinforced teeth. The other types of intraradicular reinforcements did not increase the fracture resistance of the immature teeth. The microstructure of both cements showed a more regular surface with the incorporation of calcium carbonate nanoparticles. The particles of the additive occupied most of the pores and hydration channels of the cements. MTA presented more calcium available in soluble forms than the calcium aluminate cement, regardless the addition of calcium carbonate nanoparticles.

\title{
Acknowledgments
}

The authors would like to thank the Coordination of the Improvement of Higher Education Personnel (Capes) and Portuguese Foundation for Science and Technology (FCT) in the framework of the HEALTHYDENT (co-financed via FEDER [PT2020], POCI-01-0145-FEDER-030708 and FCT [PIDDAC]).

\author{
Conflict of interest \\ The authors report no conflicts of interest.
}

\section{Resumo}

Este estudo avaliou a resistência à fratura de dentes imaturos simulados reforçados com cimento de aluminato de cálcio (CAC) ou trióxido agregado mineral (MTA) contendo nanopartículas de carbonato de cálcio (nano-CaCO3). 0 arranjo microestrutural dos cimentos e sua constituição química também foram avaliados. Quarenta e oito caninos simulando dentes imaturos foram distribuídos em 6 grupos $(\mathrm{n}=8)$ : Controle negativo - sem plug apical ou obturação do canal radicular; $C A C$ - plug apical com CAC; CAC/nano-CaCO3 - plug apical com CAC + 5\% nano-CaC03; MTA - plug apical com MTA; MTA/nanoCaCO3 - plug apical com MTA + 5\% nano-CaCO3; e Controle positivo - obturação dos canais radiculares com MTA. A resistência à fratura foi avaliada em máquina universal de ensaios. Amostras dos cimentos foram analisadas em Microscópio Eletrônico de Varredura (MEV) para determinar seu arranjo microestrutural. A análise química dos cimentos foi realizada por Espectroscopia de Energia Dispersiva de Raio-X (EDS). A resistência à fratura de $\mathrm{CAC} /$ nano-CaCO3 foi significativamente maior do que 0 controle negativo $(p<0,05)$. Não houve diferença significativa entre os outros grupos $(p>0,05)$. Ambos os cimentos apresentaram microestrutura mais regular com a adição de nano-CaC03. As amostras de MTA apresentaram mais cálcio disponivel em formas solúveis do que CAC. A adição de nano-CaC03 ao CAC aumentou a resistência à fratura dos dentes em comparação aos dentes não reforçados. A microestrutura de ambos os cimentos contendo nano-CaCO3 foi semelhante, com uma distribuição mais homogênea de cristais de formato lamelar e prismático. MTA apresentou mais cálcio disponivel nas formas solúveis do que CAC. 


\section{References}

1. Çiçek E, Yilmaz N, Koçak MM, Saglam BC, Koçak S, Bilgin B. Effect of mineral trioxide aggregate apical plug thickness on fracture resistance of immature teeth. J Endod 2017; 43:1697-1700.

2. Jamshidi D, Majd NM, Shahabi S, Arvin A, Omidi BR. Impact and fracture strength of simulated immature teeth treated with mineral trioxide aggregate apical plug and fiber post versus revascularization. J Endod 2018; 44:1878-1882.

3. Marciano MA, Camilleri J, Lucateli RL, Costa RM, Matsumoto MA, Duarte M. Physical, chemical, and biological properties of white MTA with additions of AIF3. Clin Oral Investig 2019; 23:33-41.

4. Bortoluzzi EZ, Broon NJ, Bramante CM, Felippe WT, Tanomaru-Filho M, Esberard RM. The influence of calcium chloride on the setting time, solubility, disintegration, and $\mathrm{pH}$ of mineral trioxide aggregate and white Portland cement with a radiopacifier. J Endod 2009; 35:550-554.

5. Ber BS, Hatton JF, Stewart GP. Chemical modification of ProRoot MTA to improve handling characteristics and decrease setting time. J Endod 2007; 33:1231-1234.

6. Ok E, Altunsoy M, Tanriver M, Capar ID, Kalkan A, Gok T. Fracture resistance of simulated immature teeth after apexification with calcium silicate-based materials. Eur J Dent 2016; 10:188-192.

7. Garcia LFR, Aguilar FG, Sabino MG, Rossetto HL, Pires-de-Souza FCP. Mechanical and microstructural characterization of new calcium aluminate cement (EndoBinder). Adv Appl Ceram 2011; 110:469-475.

8. Garcia Lda F, Huck C, Menezes de Oliveira L, de Souza PP, de Souza Costa CA. Biocompatibility of new calcium aluminate cement: tissue reaction and expression of inflammatory mediators and cytokines. J Endod 2014; 40:2024-2029.

9. Garcia Lda F, Huck C, Scardueli CR, de Souza Costa CA. Repair of bone defects filled with new calcium aluminate cement (EndoBinder). J Endod 2015; 41:864-780.

10. Bernardi A, Bortoluzzi EA, Felippe WT, Felippe MCS, Wan WS, Teixeira CS. Effects of the addition of nanoparticulate calcium carbonate on setting time, dimensional change, compressive strength, solubility and pH of MTA. Int Endod J 2017; 50:97-105.

11. Teixeira CDS, Wasielewsky JC, Dos Santos GS, Bernardi A, Bortoluzzi EA, Garcia LDFR. Effect of the addition of nanoparticles of $\mathrm{CaCO} 3$ and different water-to-powder ratios on the physicochemical properties of white Portland cement. Microsc Res Tech 2021; 84:592-601.

12. Camiletti J, Soliman AM, Nehdi ML. Effect of nano-calcium carbonate on early-age properties of ultra-high-performance concrete. Mag Concr Res 2013; 65:297-307.

13. Soares CJ, Pizi ECG, Fonseca RB, Martins LRM. Influence of root embedment material and periodontal ligament simulation on fracture resistance tests. Braz Oral Res 2005; 19:11-16.

14. Seto B, Chung KH, Johnson J, Paranjipe A. Fracture resistance of simulated immature maxillary anterior teeth restored with fiber posts and composite to varying depths. Dent Traumatol 2012; 29:394398.

15. Linsuwanont $P$, Kulvitit $S$, Santiwong B. Reinforcement of simulated immature permanent teeth after mineral trioxide aggregate apexification. J Endod 2018; 44:163-167.

16. Stuart $\mathrm{CH}$, Schwartz SA, Beeson TJ. Reinforcement of immature roots with a new resin filling material. J Endod 2006; 32:350-353.

17. Yang $H$, Che $Y$, Leng $F$. High volume fly ash mortar containing nano-calcium carbonate as a sustainable cementitious material: microstructure and strength development. Sci Rep 2018; 8:16439.

18. Duarte MA, Alves de Aguiar K, Zeferino MA et al. Evaluation of the propylene glycol association on some physical chemical properties of mineral trioxide aggregate. Int Endod J 2012; 45:565-570.

19. Oliveira IR, Pandolfelli VC, Jacobovitz M. Chemical, physical and mechanical properties of a novel calcium aluminate endodontic cement. Int Endod J 2010; 43:1069-1076.

20. Pires-de-Souza Fde C, Moraes PC, Garcia Lda F, Aguilar FG, Watanabe E. Evaluation of pH, calcium ion release and antimicrobial activity of a new calcium aluminate cement. Braz Oral Res 2013; 27:324-330.

21. Elnaghy $A$, Elsaka S. Fracture resistance of simulated immature roots using Biodentine and fiber post compared with different canal-filling materials under aging conditions. Clin Oral Investig 2020; 24:1333-1338. 
22. Tanalp J, Dikbas I, Özlem M, Ersev H, Güngör T, Bayrl G. Comparison of the fracture resistance of simulated immature permanent teeth using various canal filling materials and fiber posts. Dent Traumatol 2011; 28:457-464.

23. Rabie $G$, Trope $M$, Garcia $C$, Tronstad L. Strengthening and restoration of immature teeth with an acid-etch resin technique. Dent Traumatol 1986; 1:246-256.

24. Rabie G, Trope M, Tronstad L. Strengthening of immature teeth during long-term endodontic therapy. Dent Traumatol 1986; 2:43-47.

25. Brito-Júnior M, Pereira RD, Veríssimo C, Soares CJ, Faria-e-Silva AL, Camilo CC, Sousa-Neto MD. Fracture resistance and stress distribution of simulated immature teeth after apexification with mineral trioxide aggregate. Int Endod J 2014; 47:958-966. 